Available online at GSC Online Press Directory

GSC Advanced Research and Reviews e-ISSN: 2582-4597, CODEN (USA): GARRC2

Journal homepage: https://www.gsconlinepress.com/journals/gscarr

(RESEARCH ARTICLE)

\title{
Water purification and larvicidal activity of seed extract, Momordica charantia
}

\author{
Madhiyazhagan Pari ${ }^{1,}{ }^{*}$, Nareshkumar Arjunan ${ }^{2}$, Umavathi Subramani ${ }^{1}$, Villavan Ramasamy ${ }^{3}$, Murugan \\ Kadarkarai ${ }^{4}$ and Vijay Chinnathambi ${ }^{1}$ \\ ${ }^{1}$ Department of Zoology, J. K. K. Nataraja College of Arts and Science, Komarapalayam-638 183, Tamilandu, India. \\ 2 Department of Zoology, Periyar University, Salem-636 011, Tamilandu, India. \\ ${ }^{3}$ Department of Zoology, Gnanamani College of Education, Namakkal-637 018, Tamilandu, India. \\ ${ }^{4}$ Department of Zoology, Bharathiar University, Coimbatore-641 046, Tamilandu, India.
}

Publication history: Received on 08 January 2020; revised on 20 January 2020; accepted on 21 January 2020

Article DOI: https://doi.org/10.30574/gscarr.2020.2.1.0001

\begin{abstract}
This study was designed to evaluate the median Lethal Concentrations of Momordica charantia seed extract against Anopheles stephensi, Aedes aegypti and Culex quinquefasciatus and also analyze the water quality parameter of mosquito bred water. Bioassays were conducted to assess the larvicidal and pupicidal of $M$. charantia seed extract against An. stephensi, Ae. aegypti and Cx. quinquefasciatus. Their efficacy was tested on twenty five number of the each species with different concentrations of seed extract ranging from $100 \mathrm{ppm}$ to $500 \mathrm{ppm}$ and the mortality was observed after $24 \mathrm{hrs}$ time interval and also water quality parameters such as water color, turbidity and pH were analyzed in the water samples (pre-treatment and post-treatment of seed extract) taken from the breeding sites of mosquitoes. The median Lethal Concentration for A. stephensi was 119.994 ppm, 149.929 ppm, 246.757 ppm, 350.041 ppm and 382.820 ppm for I, II, III, IV Instar and pupae, respectively. Similarly, median Lethal Concentration for A. aegypti was 51.820 ppm (I Instar), 164.843 ppm (II Instar), 228.001 ppm (III Instar), 336.137 ppm (IV Instar) and 354.26 ppm (Pupae) and median Lethal Concentration for C. quinquefasciatus was 80.973 ppm, 146.755 ppm, 239.018 ppm, 333.758 ppm and 370.418 ppm for I, II, III, IV Instar and Pupae, respectively. Water quality parameters of mosquito bred water showed improved qualities in water color, turbidity and $\mathrm{pH}$ after the treatment at very low dosage. Overall of this results emphasized that the $M$. charantia seeds extract to be an effective mosquito control agent and water purification mediator.
\end{abstract}

Keywords: Momordica charantia; Diseases; Biocontrol; Purification; Parameters

\section{Introduction}

Mosquitoes are one of the deadliest animals in the world [WHO Portal, who/cds/whopes/gcdpp/13]. There are more than 3.500 species in the mosquito family. Particularly true for the chief genera which vector human disease causing pathogens-Anopheles (Malaria) Aedes (Yellow fever, dangue, chikungunya) and Culex (filariasis) mosquito are distributed globally. Their ability to carry and spread disease to humans causes millions of deaths every year [WHO Portal, https://www.who.int/neglected_diseases/vector_ecology/mosquito-borne-diseases/en/].

According to WHO [WHO Portal, http://www.who.int/malaria/publications/world-malaria-report-2017/en/] report 91 countries and areas with ongoing malaria transmission in 2016, there were an estimated 216 million cases of malaria, an increase of about 5 million cases over 2015. Deaths reached 445000 , a similar number to the previous year. According to the National Vector Borne Disease Control Programme [NVDCP Portal, https://nvbdcp.gov.in/index4.php?lang=1\&level=0\&linkid=431\&lid=3715https: //www.who.int $/ \mathrm{malaria} / \mathrm{media} /$ worl

\footnotetext{
${ }^{*}$ Corresponding author

E-mail address: madhiyazhaganpari@yahoo.com
}

Copyright (C) 2020 Author(s) retain the copyright of this article. This article is published under the terms of the Creative Commons Attribution Liscense 4.0. 
d-malaria-report-2018/en/], in 2015, the total dengue cases in India were 99,913 while for the same in 2019 they numbered $1,36,422$.

Aedes aegypti, the dengue mosquito, is found in urban areas capable of carrying many viral diseases causing pathogens including Zika, Dengue, Chikungunya, Yellow fever, and Rift Valley disease. Although the range of this mosquito was originally confined to localize tropical and subtropical regions reports confirm its presence and effects in temperate zones [WHO Portal, https://www.who.int/csr/don/4-february-2019-denguejamaica/en/]. Culex, the principal vectors of West Nile fever, St. Louis encephalitis, and Japanese encephalitis distributed worldwide in tropical and temperate regions. Lymphatic filariasis, commonly known as elephantiasis, is a neglected tropical disease set to infect 856 million people in 52 countries who require preventive chemotherapy to stop the spread of infection. The global baseline estimate of people affected by lymphatic filariasis was 25 million men with hydrocele and over 15 million people with lymphoedema. At least 36 million people remain with these chronic disease manifestations [WHO Portal, https://www.who.int/news-room/fact-sheets/detail/lymphatic-filariasis]. Anopheles, the fresh water dwellers affected around 219 million people worldwide during the year 2017. Most malaria cases were in the African Region (200 million or 92\%), followed by the South-East Asia Region with $5 \%$ of the cases and the Eastern Mediterranean Region with 2\%. Further they accounted for 61\% (266 000] of all malaria deaths worldwide [WHO Portal, http://apps.who.int/iris/bitstream/10665/85379/1/9789241505604eng.pdf?ua=1].

Larvicides, including insecticides, insect growth regulators, microbial larvicides, and oils have varying modes of action. Oils and alcohols suffocate the mosquito larvae and pupae by covering the surface of a water body; Organophosphates inhibit cholinesterase and affect the central nervous system of the mosquitoes; Insect growth regulators (such as pyriproxyfen, methoprene, and diflubenzuron) interfere with insect metamorphosis and prevent adult emergence from the pupal stage; Microbial larvicides such as Bacillus thuringiensis israeliensis (Bti) and Bacillus sphaericus (Bs) function by releasing toxins into the larvae gut which cause the larvae to stop eating and die; Plant products acts based on the active chemical present in it [1].

The alternative vector control strategies, with low cost, environment friendly and effective are extremely imperative. The use of different parts of locally available plants and their various products in the control of mosquitoes has been well established globally by numerous researchers. Especially, plant seed extracts are important natural alternatives to insecticides [2]. Seeds have been found to contain chemicals which are more effective than the leaves in controlling insects [3] and are useful for field applications in mosquito control programmes [4].

To overcome this challenge, a large number of botanical products, including plant extracts, essential oils, and pure metabolites, have been successfully proposed for the eco-friendly control of mosquito vectors and other blood-sucking Diptera $[5,6,7]$.

The plant Momordica charantia commonly known as Bitter melon or Bitter. It's widely distributed in China, Malaysia, India and Tropical Africa. Its commonly consumed as leaf, seed, and vegetable but is best remarked for its popular use in medicine, food, etc., M. charandia extract have been found suitable for different diseases and problems several researchers had reported in [8,9] controlling eye disorders and enhancing eyesight due to the presence of betacarotene. M. charantia contains an collection of biologically active plant chemicals including triterpens, proteins, steroids, alkaloids, saponins, flavonoids and acids due to which plant possesses anti-fungal, anti-bacterial, anti-parasitic, anti-viral, anti-fertility, anti-tumorous, hypoglycemic and anti-carcinogenic properties [4].

M. charantiais toxic to insects, in addition to repellent and anti-feeding effects on some agricultural insect pests and insect of medical importance (mosquito) $[10,11,12,13]$. Studies have also proved that the leaf powder of $M$. charantia is effective against Culex maculates, a stored grain pest $[14,15]$.

Natural plant extracts have been used for water purification for many centuries. Most of these extracts are derived from the seeds, leaves, pieces of bark or sap, roots and fruit extracts of trees and plants [16]. Sanghiet al. [17] reported that seeds of the nirmali tree, Strychnos potatorum were used to clarify turbid river water 4,000 years ago in India.

The above scientific fact clearly states that plant products could be an alternative to chemical insecticide and water purifiers. Common diseases causing mosquito species dwell comfortably in potable water in and around human habitat, Hence, the mosquito control agent should be non-toxic to human and other non-target organisms. Instead the mosquito control agent could also be a water purifier which also avoids few mosquito species for breeding. This is an attempt to evaluate the larvicidal efficacy of the seed extracts from the Momordica charantia against three medically important species, Anopheles stephensi, Aedes aegypti and Culex quinquefasciatus and also to investigate the water purification properties of the said plant from different water bodies were mosquito breed. 


\section{Material and methods}

\subsection{Collection of Momordica charantia seeds}

The seeds of $M$. charantia, were collected from Market areas of Sankari Taluk, Salem District, Tamil Nadu, India. The seeds have been deposited in the Department of Zoology, J.K.K. Nataraja College of Arts and Science, Tamilnadu, India.

\subsection{Preparation of Momordica charantia seeds extract}

The collected seeds were washed with tap water, shade tried at room temperature. The tried seeds were powdered with electrical blender. The powdered seeds $(1.0 \mathrm{~kg})$ were then subjected to extraction in ethanol $(5.0 \mathrm{~L}) \mathrm{using}$ Soxhlet extraction apparatus for 8 hours individually. The extract was filter through a Buchner funnel with Whatman number 1 paper. The filtrate was evaporated to dryness under reduced pressure using rotary vacuum evaporator. The residue was then made in to a $1 \%$ stock solution with ethanol. From the stock solutions, different concentrations $(100 \mathrm{ppm}$, $200 \mathrm{ppm}, 300 \mathrm{ppm}, 400 \mathrm{ppm}$ and 500ppm) were prepared and these solutions were used for larrvicidal and pupicidal activities.

\subsection{Mosquito rearing}

The eggs of Ae. aegypti, An. Stephensi and Cx. Quinquefasciatus were collected from different water bodies in Sankari Taluk, Salem District, Tamil Nadu, India. These eggs were brought to the laboratory and were transferred to $18 \mathrm{X} 13 \mathrm{X}$ $4 \mathrm{~cm}$ size enamel trays containing $500 \mathrm{ml}$ of water and kept for larval hatching. The mosquito larval culture was maintained in our laboratory at $27+2^{\circ} \mathrm{C}, 75-85 \% \mathrm{RH}$, under14L: $10 \mathrm{D}$ photoperiod cycles. The mosquito larvae were fed with dog biscuits and yeast at 3:1 ratio. The feeding was continued till the larvae were transformed into pupae. The pupae were collected from the culture trays and were transferred to plastic containers $(12 \mathrm{X} 12 \mathrm{~cm}) \mathrm{containing} 500 \mathrm{ml}$ of water. The plastic jars were kept in 90 X 90 X $90 \mathrm{~cm}$ sized mosquito cage for adult emergence. The freshly emerged adults were maintained $27 \pm 2{ }^{\circ} \mathrm{C}, 75-85 \% \mathrm{RH}$, under $14 \mathrm{~L}$ : $10 \mathrm{D}$ photoperiod cycles. The adults were fed with $10 \%$ sugar solution for a period of three days before they were provided an animal for blood feeding. The female mosquitoes were allowed to feed on the blood of a rabbit (exposed on the dorsal side) for two days (The ethical committee authorization CPCSEA Number: 887/PO/Re/S/2005/CPSEA, authorized by J.K.K. Nataraja College of Pharmacy, Komarapalayam-638 183.). The males were provided with $10 \%$ glucose solution on cotton wicks. The cotton was always kept moist with the solution and changed every day. An egg trap (cup) lined with filter paper containing water was placed at a corner of the cage egg collection.

\subsection{Larvicidal and pupicidal activity}

The larvicidal and pupicidal bioassay were assessed by using standard WHO protocols [1]. Laboratory colonies of mosquito larvae/pupae were used for the larvicidal/pupicidal activity. Twenty-five numbers of I to IV instar larvae and pupae were introduce into $500 \mathrm{ml}$ glass beaker containing $249 \mathrm{ml}$ of de-chlorinated water and $1 \mathrm{ml}$ of desired concentrations of biopesticide. Larval food was given for the test larvae. At each tested concentration 5 trials were made and each trial consisted of three replicates. The larvae/pupae exposed to de-chlorinated water without biopesticide served as control. The control mortalities were corrected by using Abbott's formula [18].

The percentage of mortality was calculated by using Abbott's formula (Abbott, 1925). The LC 50 , LC90, 95 percent confidence limit of lower confident limit (LCL) and upper confidence limit (UCL) and chi-square values were calculated by using profit analysis [19].

$$
\text { Corrected mortality }=\frac{\text { Observed mortality in treatment }- \text { Observed mortality in control }}{100-\text { Control mortality }} \times 100
$$

$$
\text { Percentage mortality }=\frac{\text { Number of dead laarvae } / \text { pupae }}{\text { Number of larvae /pupae introduced }} \times 100
$$

\subsection{Water quality parameters}

Water quality parameters such as $\mathrm{pH}$, color and turbidity were investigated using the methods of Clescerl et al. [20]. One sample containing $1000 \mathrm{ml}$ from each site was collected and required quantity was used based on standard protocol. The response variables $\mathrm{pH}$, color and turbidity are selected as preliminary variables which could make the water $50 \%$ potable. The pre-treated water was called as raw water. To prepare the coagulants and treatment [21], seeds of $M$. 
charantia seeds were shade-dried, powdered using an electric blender, and mixed with a small amount of clean water to form a paste. The paste was diluted to the required strength based on raw water turbidity. Total suspended solids in raw water separated as over 50, between 50 and 150, and over $150 \mathrm{mg} / \mathrm{l}$, and the final concentration used for treatment was 50, 30-100 and over $150 \mathrm{mg} / \mathrm{l}$, respectively. After filtering insoluble material with a fine-mesh screen or muslin cloth, the coagulant was added and stirred fast for 30s. The experiment is setup in triplicate. The treated water was then covered for $1 \mathrm{~h}$ without disturbance.

\subsection{Statistical analysis}

All data were subjected to Analysis of Variance (ANOVA) and the mortality data met parametric status. LC 50 and LC 90 values and their $95 \%$ confidence limits were estimated by getting a probit regression model to the observed relationship between percentage mortality of larvae and logarithmic concentration of the substance. The goodness of fitness of the model was tested using Chi-Square test AP value of less than 0.05 was considered as a significant departure of the model from the observations. In case of significant departure a heterogeneity factor was used to calculate the $90 \%$ confidence limit for $\mathrm{LC}_{50}$ and $\mathrm{LC}_{90}$. All analysis was carried out using SPSS Software version 16.0.

\section{Results}

The mortality data and the toxic effect of seed extracts of Momordica charantia at different concentrations on the larval instars and pupae of Anopheles stephensi, Aedes aegypti and Culex quinquefasciatus are given in (figure 1). After the treatment of seed extract. Maximum mortality was noted in all larval instars of three mosquito species. Against Anopheles stephensi lowest mortality rate (21.8\%) was observed in pupae at 100 ppm concentration of seed extract of M. charntia. $\mathrm{LC}_{50}$ values were calculated using the observed mortality. The $\mathrm{LC}_{50}$ values for seed extracts of $M$. charantia are 120.0 ppm, 150.0 ppm, 247.0 ppm, 350.0 ppm and 383.0 ppm for I, II, III, IV larval instars and pupae respectively (given in table 1). The obtained chi-square values states that there is no much difference between the expected and observed mortality. The chi-square values were significant at $\mathrm{p}<0.05$ level. The similar trends has been noted all treatments.

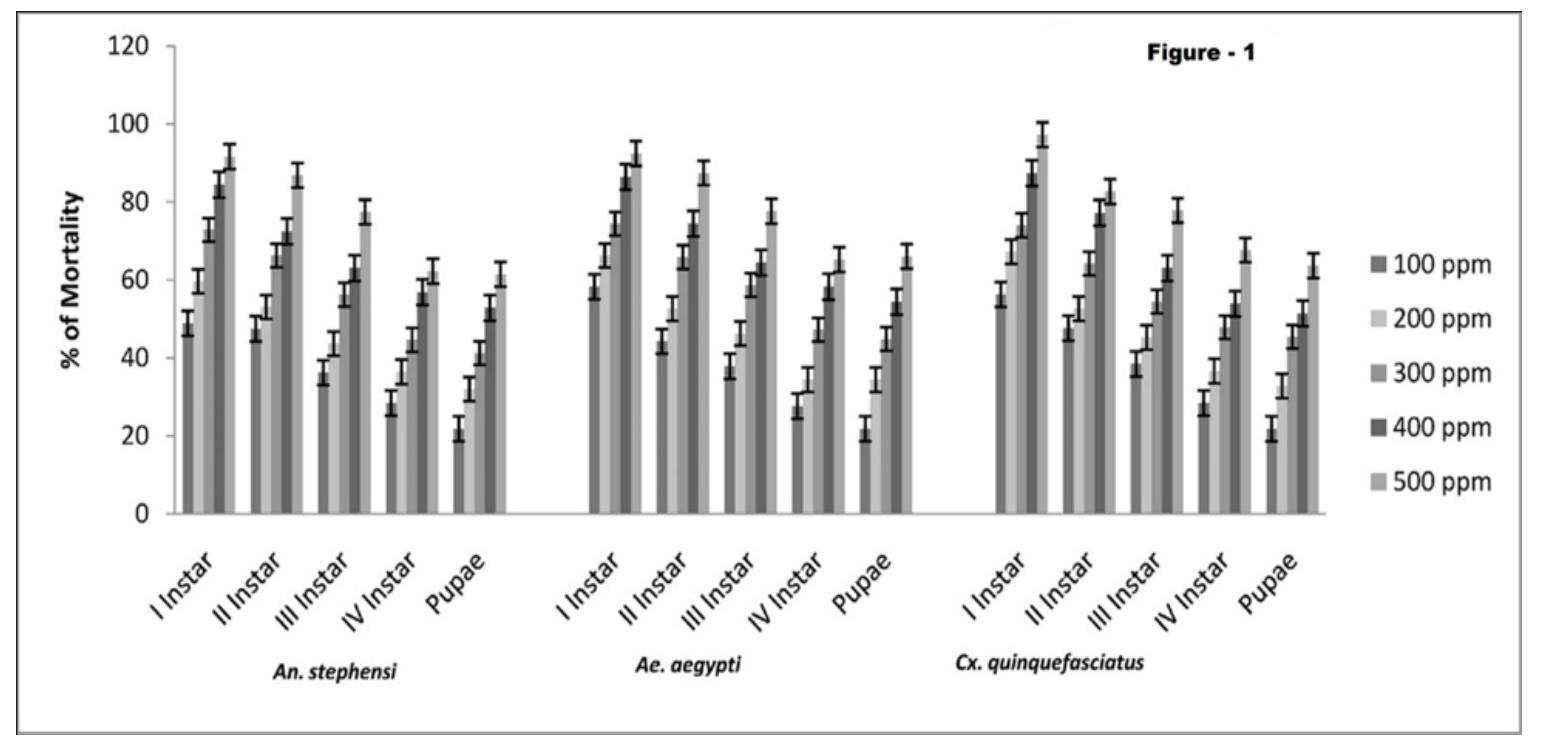

Figure 1 Mortality percentage of Momortica charantia against Anopheles stephensi, Aedes aegypti and Culex quinquefasciatus

Considerable mortality was evident after the treatment of $M$. charantia against Ae. aegypti for the all larval instars and pupae. Mortality was increased as concentration increased, for example $21.8 \%$ mortality of $M$. charantia at 100 ppm whereas; it has been increased to $92.4 \%$ at 500 ppm of $M$. charatia treatment. Similarly, the same trend has been noted for all larval stages and pupae of Ae aegypti at different concentration of $M$. charantia treatment.The LC 50 values represented as follows; LC 50 value of I Instar (52.0 ppm), II Instar (165.0 ppm), III Instar (228.0 ppm), IV Instar (336.0 ppm) and Pupae (354.0 ppm), respectively (Table 1).

The mortality data and toxic effect of $M$. charantia seed extracts at different concentrations on larval instars and pupae of filarial vector, Cx. Quinquefasciatus are also reported here (figure 1). The percentage mortality rate observed at 500 
ppm concentration was maximum (97.2\%) except in IV instar larvae (67.6\%) and in pupae (63.6\%). The observed mortality rate at $100 \mathrm{ppm}$ are $56.2 \%, 47.6 \%, 38.4 \%, 28.4 \%$ and $21.8 \%$ for I, II, III, IV and pupae, respectively. LC 50 values calculated from the observed mortality are 81.0ppm for I Instar; 147.0 for II Instar; 239.0 ppm for III Instar; 334.0 ppm for IV Instar; 370.0 ppm for Pupae (Table 1). The Chi-Square values were significant at $\mathrm{p}<0.05$ level.

Table 1 Larvicidal and pupicidal effect of Momortica charantia against Anopheles stephensi, Aedes aegypti and Culex quinquefasciatus

\begin{tabular}{|c|c|c|c|c|c|}
\hline & \multirow[t]{3}{*}{ Larval instars } & \multirow[t]{3}{*}{ LC 50} & \multicolumn{2}{|c|}{ 95\% Confidence limit } & \multirow{3}{*}{ d.f. } \\
\hline & & & LCL & UCL & \\
\hline & & & LC50 & $\mathbf{L C}_{50}$ & \\
\hline \multirow[t]{10}{*}{ Anopheles stephensi } & I & & & & $\mathrm{f}=17.53577$ \\
\hline & & 120.0 & 55.0 & 164.0 & $p=0.005765$ \\
\hline & II & 1500 & 760 & 1980 & $\mathrm{f}=18.64944$ \\
\hline & & 150.0 & 10.0 & 190.0 & $p=0.004991$ \\
\hline & III & 2470 & 1050 & 2000 & $f=19.93970$ \\
\hline & & $24 \pi .0$ & 190.0 & 209.0 & $p=0.004258$ \\
\hline & IV & 2500 & 3010 & ח & $f=21.42466$ \\
\hline & & 350.0 & 301.0 & 412.0 & $p=0.003583$ \\
\hline & Pupae & 2820 & 2200 & 4420 & $f=21.83780$ \\
\hline & & 300.0 & 359.0 & 442.0 & $\mathrm{p}=0.003420$ \\
\hline \multirow[t]{10}{*}{ Aedes aegypti } & I & 520 & 540 & 1140 & $f=17.37077$ \\
\hline & & $5 \angle .0$ & 54.0 & 114.0 & $p=0.005893$ \\
\hline & II & 1650 & 1020 & 2000 & $f=18.57064$ \\
\hline & & 105.0 & 103.0 & 208.0 & $p=0.005041$ \\
\hline & III & 2200 & 1600 & ח 272 & $f=19.74665$ \\
\hline & & $2 \angle 8.0$ & 109.0 & $2 / 2.0$ & $p=0.004358$ \\
\hline & IV & 2260 & 2100 & 2070 & $f=21.19015$ \\
\hline & & 330.0 & 340.0 & $38 \% .0$ & $p=0.003679$ \\
\hline & Pupae & 2540 & 2150 & ת & $f=21.38104$ \\
\hline & & 304.0 & 310.0 & 402.0 & $p=0.00360$ \\
\hline \multirow[t]{10}{*}{ Culex quinquefasciatus } & I & 810 & 70 & 1200 & $f=17.12296$ \\
\hline & & 01.0 & 1.0 & 129.0 & $p=0.006092$ \\
\hline & II & 1470 & 650 & 1000 & $f=18.72663$ \\
\hline & & 147.0 & 03.0 & 170.0 & $p=0.004943$ \\
\hline & III & & & & $f=19.94029$ \\
\hline & & 239.0 & 184.0 & 284.0 & $p=0.004258$ \\
\hline & IV & 2240 & 2800 & 2860 & $f=12.70049$ \\
\hline & & 504.0 & 200.0 & 500.0 & $p=0.007360$ \\
\hline & Pupae & 3700 & 3290 & 4240 & $f=21.63247$ \\
\hline & & 370.0 & $3<9.0$ & 424.0 & $\mathrm{p}=0.00350$ \\
\hline
\end{tabular}

Mortality rates are means \pm SD of five replicates; No mortality was observed in the control; Within each row, means followed by the same letter[s] are not significantly different $[\mathrm{P}<0.05] ; \mathrm{LC}_{50}=$ lethal concentration that kills $50 \%$ of the exposed organisms; $\mathrm{LC}_{90}=$ lethal concentration that kills 90 $\%$ of the exposed organisms; LCL = lower confidence limit; UCL = upper confidence limit; $\chi^{2}=$ chi-square value; $d . f .=$ degrees of freedom; $n . s .=$ not significant $[\mathrm{P}<0.05]$ 
Water purification properties of $M$. charantia seed extract which includes parameters viz., water color, total suspended solids and $\mathrm{pH}$ are produced in figure 2. Before treatment, the drinking water color (31 HU), Tap water (40 HU) and stagnant water (46 HU) while after the treatment, the colour was significantly reduced $14 \mathrm{HU}, 18 \mathrm{HU}$ and $21 \mathrm{HU}$, respectively. The water colour was deviated ranging from $17 \mathrm{HU}$ to $25 \mathrm{HU}$, respectively. Total suspended solids before treatment in the drinking water $40.0 \mathrm{mg} / \mathrm{l}$, in tap water $42.0 \mathrm{mg} / \mathrm{l}$ and in stagnant water $45.0 \mathrm{mg} / \mathrm{l}$ and it was reduced after the treatment 32.0, 36.0 and $39 \mathrm{mg} / \mathrm{l}$, respectively. The Total suspended solid was deviated ranging from $6 \mathrm{mg} / \mathrm{l}$ to $8 \mathrm{mg} / \mathrm{l}$, respectively. Similarly, $\mathrm{pH}$ level was 8.0, 8.4 and 8.9 before treatment of Drinking water, tap water and stagnant water, respectively and the $\mathrm{pH}$ level significantly reduced after the treatment of $M$. charantia seed extract the $\mathrm{pH}$ values are $6.9,7.6$, and 7.9 , respectively. The $\mathrm{pH}$ was deviated from 0.8 to 1.1 , respectively.

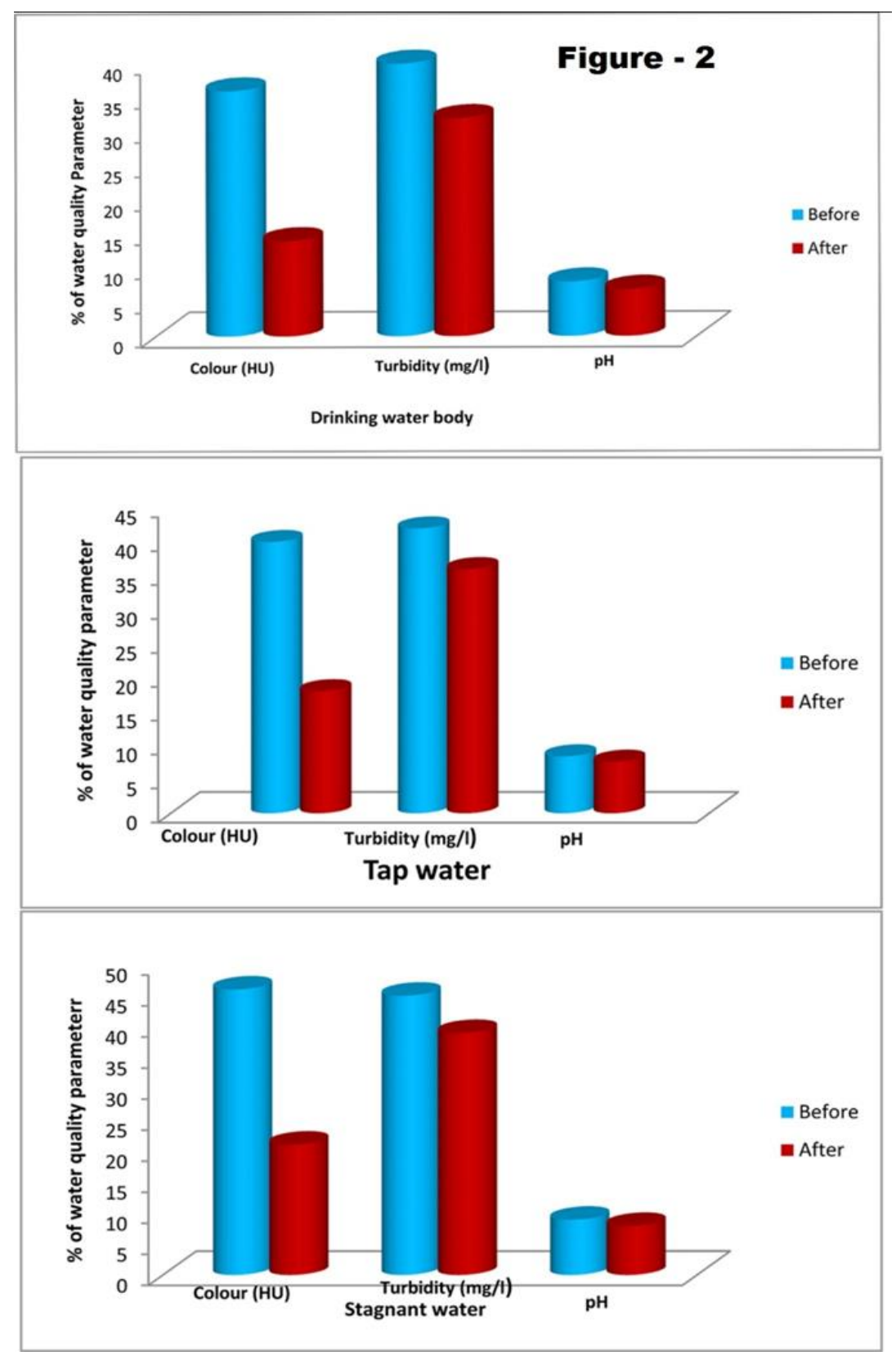

Figure 2 Water quality parameter of mosquito bred water before and after the treatment of seed extract, Momortica charantia. 


\section{Discussion}

Generally the active toxic ingredients of plant extracts are secondary metabolites that are evolved to protect them from herbivores. The insects feed on these secondary metabolites potentially encountering toxic substances with relatively non-specific effects on a wide range of molecular targets. These targets range from proteins (enzymes, receptors, signaling molecules, ion-channels and structural proteins), nucleic acids, bio-membranes, and other cellular components. This in turn, affects insect physiology in many different ways and at various receptor sites, the principal of which is abnormality in the nervous system (such as, in neurotransmitter synthesis, storage, release, binding, and reuptake, receptor activation and function, enzymes involved in signal transduction pathway) [22]. This present study agree with above scientific fact because, $M$. charantia which consist the active components including triterpens, proteins, steroids, alkaloids, saponins, flavonoids [4] this secondary metabolites which may be reason for the larval and pupal mortality of three economically important mosquitoes namely, Ae. aegypti, An. Stephensi and C. quinquefasciatus.

The phytochemical of $M$. charantia seed reveals the presence of alkaloids, tannins and saponins. These compounds are known to be biologically active. Tannins have important roles such as stable and potent antioxidants [23]. Herbs that have tannins as their main component are astringent in nature and are used for treating intestinal disorders such as diarrhea and dysentery [24]. That of the largest group of chemicals produced by plants are the alkaloids and their amazing effect on humans has led to the development of powerful pain killer medications [25].

Earlier insecticidal activity of $M$. charantia was confirmed by Kumar et al. [26]. Subramaniam et al. [12] studied the larvicidal activities of methanol extracts from leaves of Momordica charantia and also provided LC information for different larval instars of An. stephensi, as experimented and described in the present study. Further the toxicological studies have shown that this plant is safe for human health, and there are no toxic effects on other non-target organisms $[27,28]$. Reports also state that this plant extract is slightly effective against Plasmodium genus in-vitro and moderate in-vivo activity on rodent malaria $P$. vinckeipetteri $[29,30]$. Singh et al. $[31]$ tested $M$. charantia against the $4^{\text {th }}$ instar of An. stephensi, Cx. quinquefasciatus and Ae. aegypti and observed mortality in high concentration ( $\mathrm{LC}_{50}$ values of 0.50 , 1.29 and $1.45 \%$ ) when compared to the present study may be due to the solvent used in the present study might have extracted more number of compounds toxic to mosquitoes.

The commercial methods for the treatment of drinking water commonly used include chlorination, solar disinfection and slow sand filtration [32]. Despite the efficacy of these methods, they are out of reach for the majority of people, particularly those in remote regions. Commercial water disinfectants are affected by the physico-chemical properties of water such as turbidity, alkalinity and concentration of organic matter [33]. The reduction of turbidity, $\mathrm{pH}$ and change in colour with different concentrations of M. charantia observed in the present study could overcome the above said problem. Products from $M$. charantia shall be commercialized as water purer or could be an additive along with the commercial disinfectants. Previously other researchers reported that water quality [potable $\mathrm{pH}$, turbidity and color] can be improved using aqueous and organic extracts of $M$. oleifera Lam [34, 35]. The characteristic bitter taste of the Momordica charantia is due to the presence of 'momordicine'. This compound could be one of the reasons that lead to enrich the taste of water at very low dosage [36].

\section{Conclusion}

The present results encourage that Momordica charantia seeds extract can be used for larvicidal and water purifying purposes for promoting water sustainability. World population increasing year to year and reaching 7 billion in 2012 whereas an access of getting pure water remains a problem especially for people who live in developing countries. The severity is much observed in rural dwellers who is their source of drinking water is surface (raw) water which is not purified and this results for transmission of waterborne diseases. Considering the fact that M. charantia seed extract coagulum can be locally produced, its use in water purification should be encouraged. This is likely to reduce the high cost of the current water treatment systems. Experiments on extract of $M$. charantia seeds for their, larvicidal, and pupicidal activity have opened the possibility of further investigations on their efficiency, in view of the utilization of their higher biomass. The study proved that the seed extracts of $M$. charantia have both mosquitocidal and water sedimentation properties. 


\section{Compliance with ethical standards}

\section{Acknowledgments}

The authors gratefully acknowledge the financial support received from Authorities of J.K.K. Nataraja Institutions, Komarapalayam-638183, Tamilnadu, India. The funder had no role in the study design, data collection and analysis, decision to publish, or preparation of the manuscript.

\section{Disclosure of conflict of interest}

The authors declare no conflicts of interest.

\section{References}

[1] Atshan KA, Tirupati Rao YRKV and Raghu Ram M. (2017). Effect of Seed Extracts as Insecticides Against Lepidopteran Pests on Cauliflower. Asian J Agricult Res, 11, 78-85.

[2] Biswas D, Mandal B, Biswas B, Banerjee A and Mukherjee TK. (2013). Plying of speedboats along canals in the city of Kolkata, India, to prevent mosquito breeding. Trans R Soc Trop Med Hyg, 107(3), 147-51.

[3] Thongwat D, Lamlertthon, Pimolsri U andBunchu N. (2017).Larvicidal activity of endocarp and seed crude extracts of Dracaena loureiri Gagnep against Aedes aegypti (L.) mosquito. Asian Pacific Journal of Tropical Biomedicine, 7(3), 222-226.

[4] Azizullah A, Rehman ZU, Ali I, Murad W, Muhammad N, Ullah W, et al. (2014). Chlorophyll derivatives can be an efficient weapon in the fight against dengue. Parasitology Research, 113, 4321-4326.

[5] Benelli G, Murugan K, Panneerselvam C, Madhiyazhagan P, Conti B and Nicoletti M. (2015). Old ingredients for a new recipe? Neem cake, a low-cost botanical by-product in the fight against mosquito-borne diseases. Parasitology Research, 114(2), 391-397.

[6] Pavela R. (2015). Essential oils for the development of eco-friendly mosquito larvicides: A review Ind Crop Prod, $76,174-187$.

[7] Cefalu WT, Ye J and Wang ZQ. (2008). Efficacy of dietary supplementation with botanicals on carbohydrate metabolism in humans. Endocrin Metab Imm Disord Drug Targets, 8, 78-81.

[8] Cousens G. (2008). There is a cure for diabetes: the tree of life 21 day programs. California: North Atlantic Books, 191-192.

[9] Lee SY, Eom SH, Kim YK, Park NI and Park SU. (2009). Cucurbitane-type triterpenoids in Momordica charantia Linn. J Med Plants Res, 3(13), 1264-1269.

[10] Zhi LL, Swee HG andShuit HH. (2007). Screening of Chinese medicinal herbs for bioactivity against Sitophilus zeamais (Motschulsky) and Tribolium castaneum (Herbst.) J Stored Prod Res, 43, 290-296.

[11] Fiaz M, Hameed A, Hasan M andWkil W. (2012). Efficacy of plant extracts on some cotton (Gossypium hirsutum) pests: Ambrasca bigutulla bigutulla Ishida and Thrips tabaci Lindemam. Pak J Zool, 44, 277-283.

[12] Subramaniam J, Murugan K andKovendan K. (2012). Larvicidal and pupcidal efficacy of Momordica charantia leaf extract and bacterial insecticide, Bacillus thuringiensis against malarial vector, Anopheles stephensi Liston. (Diptera: Culicidae). J Biopest, 5, 163-169.

[13] Hameed AFH, Shah M, Abid B, Siddique SK, Nabi A, Amin AM. et al. (2013). Comparative efficacy of five medicinal plant extracts against Rosa indica insect pests and elaboration of hazardous effects on pollinators and predators. Pak Entomol, 35,145-150.

[14] Boeke SJ, Kossou DK, Van Huis A, Van Loon JJA and Dicke M. (2004). Field trials with plant products to protect stored cowpea against insect damage. International Journal of Pest Management, 50, 1-9.

[15] Adesina JM, Afolabi LA andOfuya TI. (2012). Evaluation of insecticidal properties of Momordica charantia in reducing oviposition and seed damaged by Callosobruchus maculatus (Fab.) Walp J ProgAgricul, 8, 493-499.

[16] Anwar F and Rashid U. (2007). Physico-chemical characteristics of Moringa oleifera seeds and seed oil from a wild provenance of Pakistan. Pak J BiolSci, 39, 1443-1453. 
[17] Sanghi R, Bhattacharya B, Dixit A and Singh V. (2006). Ipomoea dasysperma seed gum: an effective natural coagulant for the decolorization of textile dye solutions. J Environ Manag, 81(1), 36-41.

[18] Abbott WS. (1925). A method of computing the effectiveness of an insecticide. J Econ Entomol, 18, 265-267.

[19] Finney DJ. (1971). Probit Analysis, third ed. Cambridge University Press, London, UK, 38.

[20] Clescerl Leonore S, Greenberg Arnold E and Eaton Andrew D. (2005). Standard methods for the examination of water and wastewater (20 th ed.). American Public Health Association, Washington, DC.

[21] Schwarz D. (2000). Water Clarification using Moringa oleifera Technical Information W1e. Gate-Tech Info, W1e, $1-7$.

[22] Rattan RS. (2010). Mechanism of action of insecticidal secondary metabolites of plant origin. Crop Protec, 29, 913-920.

[23] Trease GE and Evans WC. (1978). A text book of pharmacognosy. 11th ed. BailliereTidall, London, 530.

[24] Dharmananda S. (2003). Gallnuts and the uses of Tannins in Chinese medicine. In; Proceedings of Institutes for Traditional Medicine, Portland, Oregon, Sources.

[25] Raffauf RF. (1996). Plant alkaloids: A guide to their discovery and distribution. Hawkworth Press, Inc., New York, NY.

[26] Kumar A, Tewari GD and Panday ND. (1979). Studies on anti-feeding and insecticidal properties of bitter gourd (Momordica charantia Linn.) against mustered saw fly Athaliaproxima. Klug Pesticides, 13(12), 9.

[27] Chopra RN. (1933). Indigenous drugs of India. The Art Press, Calcutta, 310.

[28] Chopra RN, Nayar SL and Chopra IC. (1956). Glossary of Indian medicinal plants. New Delhi: Publication and Information Directorate, Council of Scientific and Industrial Research, 229.

[29] Yousif Ali S. (2014). In vitro screening of anti-plasmodium activity of Momordica charantia. STU, 2(3), 29-33.

[30] Amorin CZ, Marques AD and Cordeino RS. (1991). Screening of the antimalarial activity of plants of the cucurbitaceae family. Memorias do Instituto Oswaldo Cruz, 86, S177-S180.

[31] Singh R, Dhiman CR and Mittal P. (2006). Mosquito larvicidal properties of Momordica charantia Linn (Family: Cucurbitaceae). Journal of Vector Borne Diseases, 43, 88-91.

[32] Acra A, Jurdi M, Mu'allem Y and Raffoul Z. (1990). Water Disinfection by Solar Radiation. International Development Research Center (IDRC), Ottawa.

[33] Crump JA, Okoth GO, Slutsker L, Ogaja DO and Keswick BH. (2004). Luby SP. Effect of point of use disinfection, flocculation and combined flocculation-disinfection on drinking water quality in western Kenya. J Appl Microbiol, 97, 225-231.

[34] Anith JR, Velliyu KG, Sangilimuthu AY and Sudarsanam D. (2011). Antimicrobial activity of Moringa oleifera (Lam.) root extract. J Pharm Res, 4, 1426-1427.

[35] Sarin R, Manvi M andSapna B. (2010). Evaluation of antibacterial potential of stem bark of M. oleifera. Lam Biosci, 1, 89-94.

[36] SuprajaBasha T, Nagaraju C, Kiranmayee P andUsha R. (2015). Identification of an alkaloid momordicin from fruits of Momordica charantia L. International J Sci Engin Res, 6(2), 168-172.

\section{How to cite this article}

Madhiyazhagan P, Nareshkumar A, Umavathi S, Villavan R, Murugan K and Vijay C. (2020). Water purification and larvicidal activity of seed extract, Momordica charantia. GSC Advanced Research and Reviews, 2(1), 01-09. 